\title{
Two new species and new record of Batricavus Yin \& Li (Coleoptera, Staphylinidae, Pselaphinae) from China
}

\author{
Zi-Wei Yin ${ }^{1, \dagger}$, Li-Zhen Li ${ }^{1, \ddagger}$ \\ I Department of Biology, College of Life and Environmental Sciences, Shanghai Normal University, Shanghai, \\ 200234, P. R. China \\ † urn:lsid:zoobank.org:author:C515106C-5782-4471-AE11-483B49606A67 \\ ¥ urn:lsid:zoobank.org:author:BBACC7AE-9B70-4536-ABBE-54183D2ABD45 \\ Corresponding author: Li-Zhen Li (lizhenli@shnu.edu.cn)
}

Academic editor: C. Majka | Received 22 June 2012 | Accepted 7 August 2012 | Published 17 August 2012

urn:lsid:zoobank.org:pub:9B685A3C-6EB5-44F5-B463-ECA848BA5D51

Citation: Yin ZW, Li LZ (2012) Two new species and new record of Batricavus Yin \& Li (Coleoptera, Staphylinidae, Pselaphinae) from China. ZooKeys 215: 33-39. doi: 10.3897/zookeys.215.3570

\begin{abstract}
Two new species, Batricavus abdominalis Yin $\& \mathrm{Li}$, sp. n. and B. hainanensis $\mathrm{Yin} \& \mathrm{Li}$, sp. n. are described from Hainan, South China, with male habitus and major diagnostic features illustrated. Batricavus tibialis Yin \& Li is newly recorded from Zhejiang, East China. Keys to both sexes of the genus are included.
\end{abstract}

\section{Keywords}

Coleoptera, Staphylinidae, Pselaphinae, Batricavus, new species, new record, China, key

\section{Introduction}

The monotypic genus Batricavus Yin \& Li presently contains only one species, B. tibialis Yin \& Li from Guangdong, South China. The genus is separated from the allies primarily by the presence of a pair of anteropronotal foveiform pits in both sexes (for further discussion see Yin et al. 2011: 530). Recently, a series of Batricavus, representing two undescribed species, was collected during an expedition to Hainan Island. In additional, two male specimens representing a new record of $B$. tibialis, collected from South Zhejiang by Jiang-Qing Zhu, became available for study. This paper will

Copyright Zi-Wei Yin, Li-Zhen Li. This is an open access article distributed under the terms of the Creative Commons Attribution License 3.0 (CC-BY), which permits unrestricted use, distribution, and reproduction in any medium, provided the original author and source are credited. 
describe the new species, provide new distribution data for known species, and present identification keys to both males and females of the genus.

\section{Material and methods}

Material treated in this study are housed in the Insect Collection of Shanghai Normal University, Shanghai, China (SNUC).

A slash (/) is used to separate lines on the same label, a double slash (//) is used to separate different labels. The terminology of the foveal system follows Chandler 2001, except for use 'ventrite' instead of 'sternite' when concerning the meso- and metathoracic structures.

The following acronyms are used in the text: $\mathbf{B L}$ - length of the body (= $\mathrm{HL}+\mathrm{PL}+\mathrm{EL}+\mathrm{AL}) ; \mathbf{H L}-$ length of the head from the anterior margin of the clypeus to the occipital constriction; HW - maximum width of the head across eyes; PL - length of the pronotum along the midline; PW - maximum with of the pronotum; EL length of the elytra along the suture; $\mathbf{E W}$ - maximum width of the elytra; $\mathbf{A L}$ - length of the abdomen along the midline; AW - maximum width of the abdomen.

\section{Taxonomy}

\section{Key to males}

1 Protibiae expanded laterally at apical 1/4 (Yin et al. 2011: 4, fig. 8) or near middle (Fig. 3A); metafemora and tergite IV simple

- $\quad$ Protibiae simple; metafemora broadened mesally at apical 1/4 (Fig. 2B); tergite IV with large median cavity (Fig. 2A). (Hainan) ... B. abdominalis sp. $\mathbf{n}$.

2 Antennomeres VIII much larger than VII (Yin et al. 2011: 4, fig. 6); protibiae expanded laterally at apical 1/4. (Guangdong, Zhejiang)

B. tibialis Yin \& $\mathrm{Li}$

- $\quad$ Antennomeres VIII smaller than VII (Fig. 1B); protibiae expanded laterally near middle. (Hainan)

B. hainanensis sp. $\mathbf{n}$.

\section{Key to females}

$1 \quad$ Elytra and abdomen scattered with long setae except for normal pubescence.. B. abdominalis sp. $\mathbf{n}$.

- $\quad$ Elytra and abdomen normally pubescent, lacking long setae ........................2 
2 Head with basomedian carina extending anteriorly to level of posterior margin of vertexal foveae; tergite VIII with smooth posterior margin (Yin et al. 2011: 533, fig. 11). B. tibialis Yin \& Li

- Head with basomedian carina extending anteriorly for very short distance, followed by short, thin sulcus reaching anteriorly and ending as small round pit at level of posterior margin of vertexal foveae; tergite VIII with serrate posterior margin (Figs 3D, E)

B. hainanensis sp. $\mathrm{n}$.

\section{Batricavus abdominalis Yin \& Li, sp. n.}

urn:lsid:zoobank.org:act:174178C3-F08F-4BD5-B9E9-EF2FAA2F120B

http://species-id.net/wiki/Batricavus_abdominalis

Figs 1A, 2

Type-locality. China, Hainan Province: Lingshui County, Diaoluoshan Natural Reserve, $18^{\circ} 43^{\prime} 36.93^{\prime \prime} \mathrm{N}, 109^{\circ} 52^{\prime} 55.21 " \mathrm{E}, 950 \mathrm{~m}$ a.s.l.

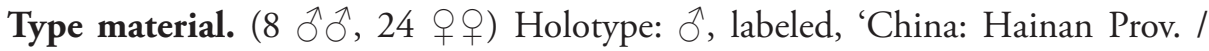
Diaoluoshan N. R. / road to reservoir / 25.iv.2012, 950 m / Pan et Li leg.'. Paratypes: $2 \widehat{O}, 8$ 우, same label data as holotype; $1 \hat{0}, 1$, same label data except 'Zi-Wei Yin leg.'; 4 ô $\partial^{\lambda}, 15$ 우, same label data except 'Dai et Peng leg.'.

Other material examined. $5 \hat{\jmath}, 6$ 우, labeled 'China: Hainan Prov. / Ledong County / Jianfengling N. R. / 15.xi.2005 / Jian-Hua Huang leg.'.

Diagnosis. Length 1.50-1.60; antennal club three-segmented, lacking obvious modification in male; male with simple protibiae and modified metafemora and tergite IV.

Description. Male. Length 1.50-1.59; body (Fig. 1A) reddish brown, maxillary palpi and tarsi lighter. Head slightly wider than long, HL 0.34-0.35, HW 0.39-0.41. Eyes each composed of about 20 large facets. Antennal club three-segmented, segment VIII smallest, IX-XI enlarged. Pronotum rounded laterally, slightly wider than long, PL 0.38-0.40, PW 0.42-0.46. Elytra wider than long, EL 0.53-0.57, EW 0.61-0.63, with scattered long setae. Protibiae simple; metafemora broadened mesally at apical 1/4 (Fig. 2B). Abdomen much narrower than elytra, AL 0.25-0.27, AW 0.53-0.55; tergite IV (Fig. 2A) with large median cavity comprising complicated structure. Aedeagus (Figs $2 \mathrm{C}, \mathrm{D}$ ) length 0.20 , well-sclerotized, with elongate dorsal lobe.

Female. Measurements: BL 1.54-1.60, HL 0.33-0.34, HW 0.40-0.41, PL 0.370.38, PW 0.41-0.43, EL 0.50-0.53, EW 0.60-0.63, AL 0.34-0.35, AW 0.56-0.58.

Generally similar to male; eyes smaller, each composed of about 15 facets; tergite VIII (Fig. 2E) with smooth posterior margin; genital complex (Fig. 2F) transverse, width 0.24 , well sclerotized.

Distribution. South China: Hainan.

Etymology. The specific epithet refers to the male sexual character present on abdominal tergite IV. 


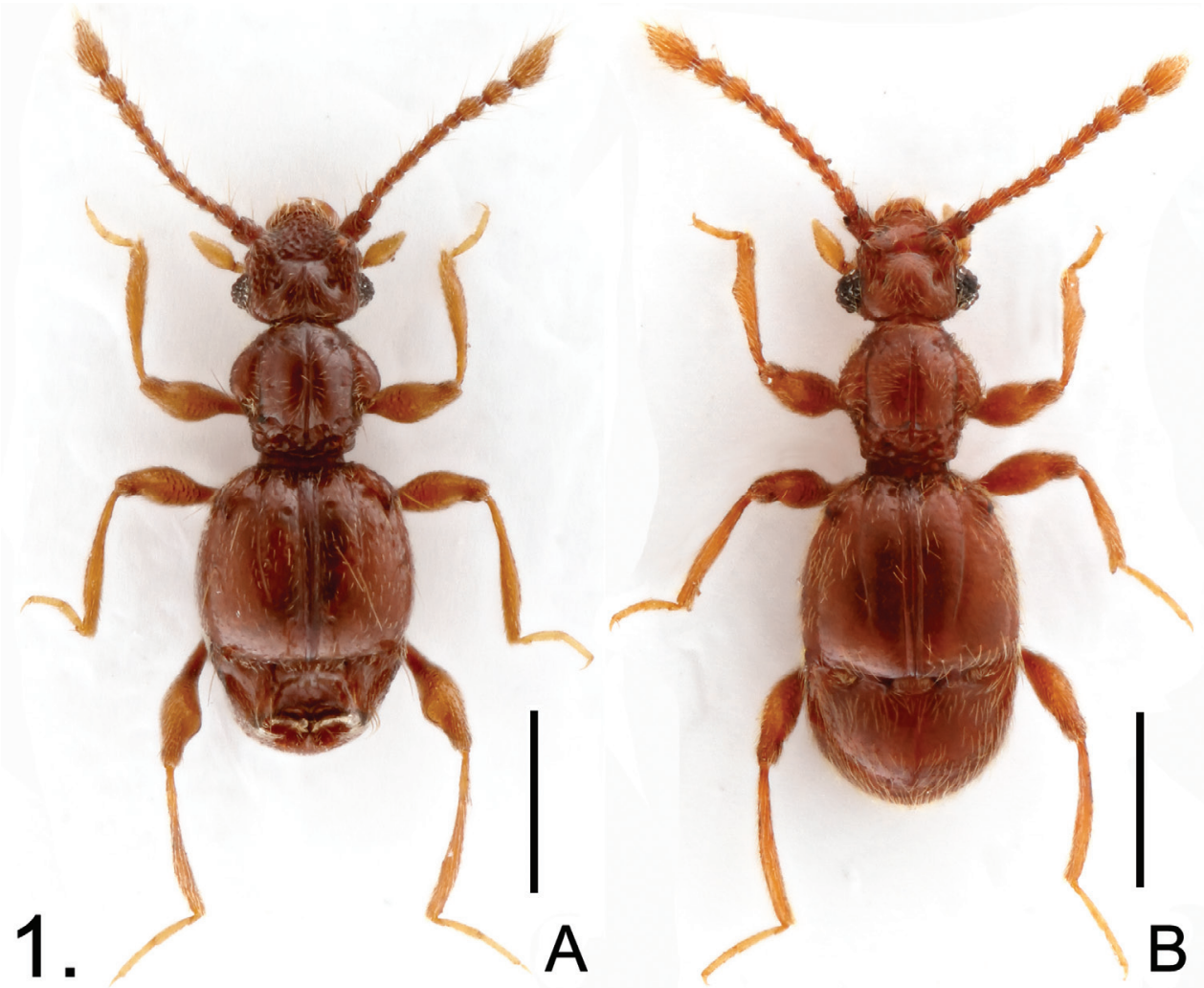

Figure I. Male habitus of Batricavus A B. abdominalis B B. hainanensis. Scales: $0.5 \mathrm{~mm}$.

\section{Batricavus hainanensis Yin \& Li, sp. n.}

urn:lsid:zoobank.org:act:B16612EB-1867-40DA-9298-6A001C992718

http://species-id.net/wiki/Batricavus_hainanensis

Figs 1B, 3

Type-locality. China, Hainan Province: Lingshui County, Diaoluoshan Natural Reserve, $18^{\circ} 42^{\prime} 18.87^{\prime \prime} \mathrm{N}, 109^{\circ} 52^{\prime} 59.48^{\prime \prime} \mathrm{E}, 720 \mathrm{~m}$ a.s.l.

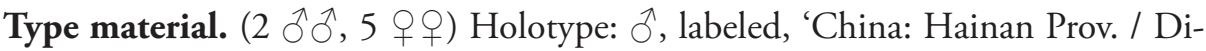
aoluoshan N. R. / disc road / 26.iv.2012, 600-1,000 m / Dai et Peng leg.'. Paratypes: $1 \hat{\delta}, 2$ 우 $ᄋ$, same label data as holotype; $1 \hat{\delta}$, same label data except 'road to reservoir / 25.iv.2012, 1,000 m’; 2 우, same label data except 'Zi-Wei Yin leg'.

Other material examined. 1 , labeled 'China: Hainan Prov. / Jianfengling N. R. / Wufenqu area / 2.v.2012, alt. 900 m / Pan et Yin leg.'.

Diagnosis. Length 1.62-1.69; antennal club weakly indicated by apical three antennomeres, lacking obvious modification in male; male with modified protibiae and simple metafemora and tergite IV. 


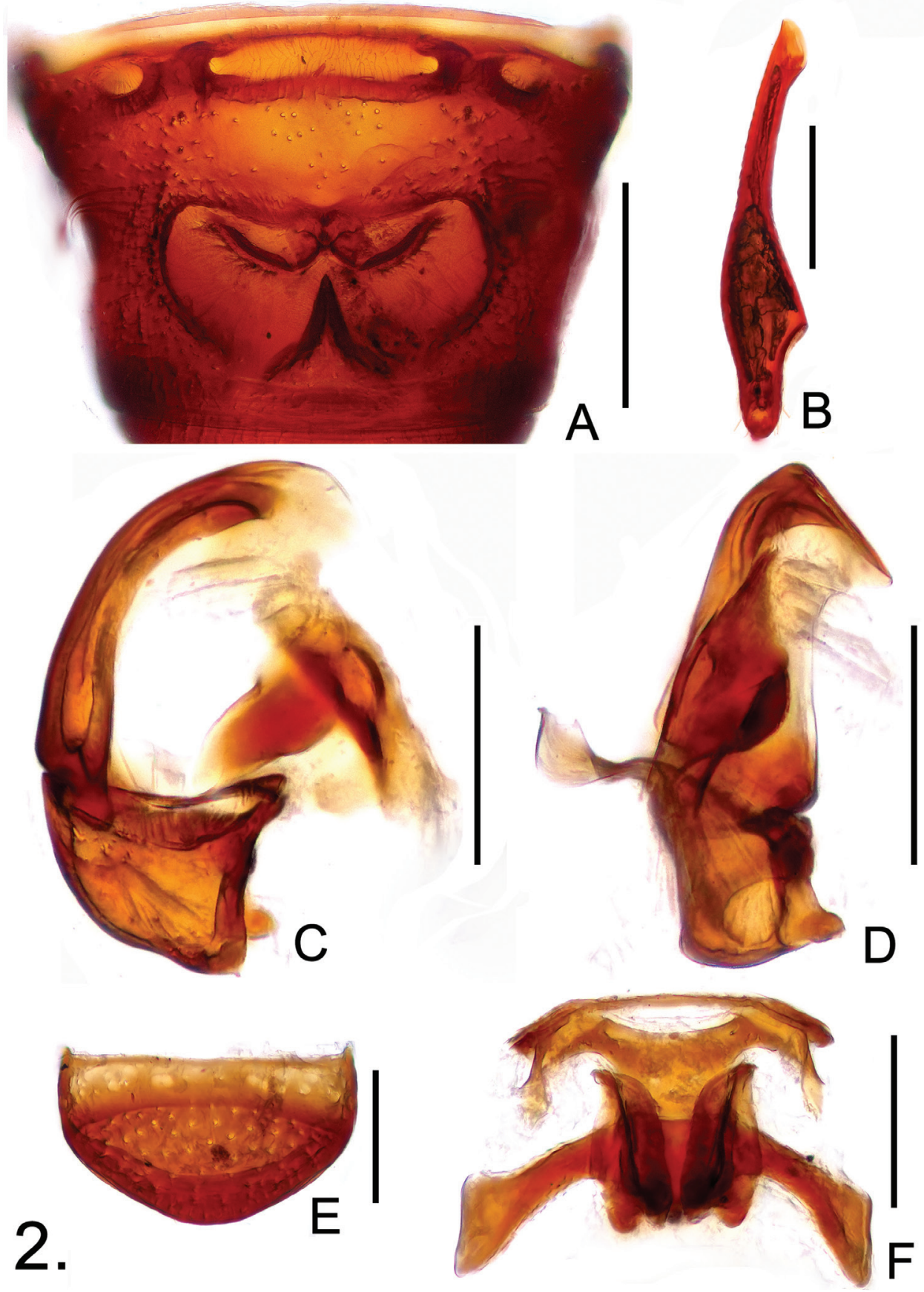

Figure 2. Diagnostic features of $B$. abdominalis $\mathbf{A}$ male tergite IV $\mathbf{B}$ male metafemur $\mathbf{C}$ aedeagus, in lateral view $\mathbf{D}$ same, in ventral view $\mathbf{E}$ female tergite VIII $\mathbf{F}$ female gential complex, in ventral view. Scales: $\mathrm{A}, \mathrm{B}=0.2 \mathrm{~mm}, \mathrm{C}-\mathrm{F}=0.1 \mathrm{~mm}$. 

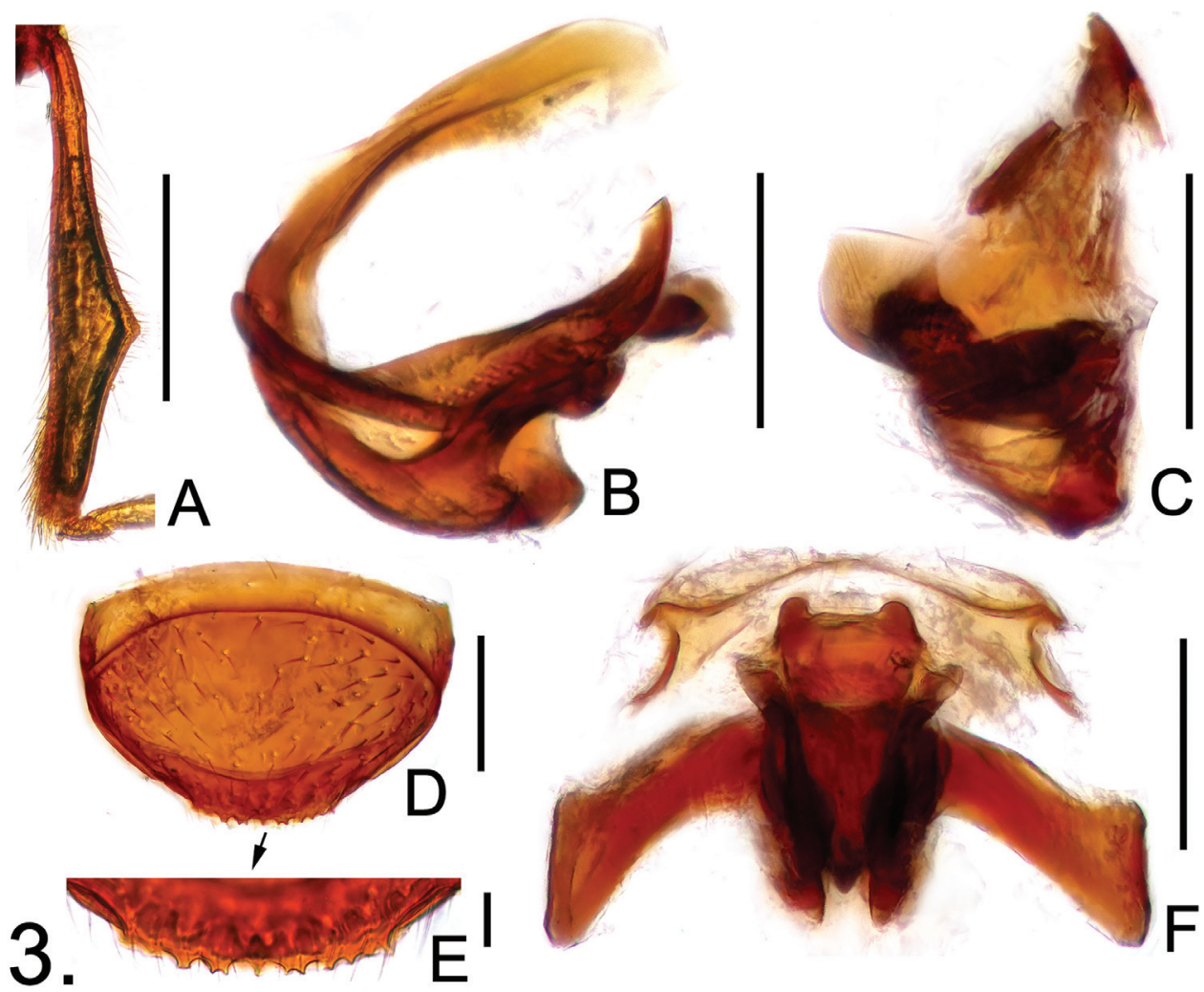

Figure 3. Diagnostic features of $B$. hainanensis $\mathbf{A}$ male protibia $\mathbf{B}$ aedeagus, in lateral view $\mathbf{C}$ same, in ventral view $\mathbf{D}$ female tergite VIII $\mathbf{E}$ same, posterior margin enlarged $\mathbf{F}$ female gential complex, in ventral view. Scales: $\mathrm{A}=0.2 \mathrm{~mm}, \mathrm{~B}-\mathrm{D}, \mathrm{F}=0.1 \mathrm{~mm}, \mathrm{E}=0.02 \mathrm{~mm}$.

Description. Male. Length 1.62-1.67; body (Fig. 1B) reddish brown, maxillary palpi and tarsi lighter. Head slightly wider than long, HL 0.32-0.33, HW 0.39-0.41. Eyes each composed of about 30 facets. Antennal club formed by apical three antennomeres, segment VIII smallest, IX-XI enlarged. Pronotum rounded laterally, about as long as wide, PL 0.39-0.40, PW 0.40-0.41. Elytra wider than long, EL 0.560.58 , EW 0.63-0.64, covered by short pubescence. Protibiae (Fig. 3A) triangularly expanded laterally near middle; metafemora simple. Abdomen narrower than elytra, AL 0.35-0.36, AW 0.58-0.59; tergite IV simple in structure. Aedeagus (Figs 3B, C) length 0.18 , well-sclerotized, with elongate dorsal lobe.

Female. Measurements: BL 1.65-1.69, HL 0.34-0.35, HW 0.40-0.41, PL 0.380.39, PW 0.40-0.41, EL 0.53-0.54, EW 0.62-0.63, AL 0.40-0.41, AW 0.58-0.60.

Generally similar to male; eyes smaller, each composed of about 25 facets; tergite VIII (Fig. 3D, E) with serrate posterior margin; genital complex (Fig. 3F) transverse, width 0.27 , well sclerotized.

Distribution. South China: Hainan.

Etymology. The specific epithet refers to the type locality. 
Batricavus tibialis Yin \& Li, 2011

http://species-id.net/wiki/Batricavus_tibialis

Batricavus tibialis Yin \& Li, 2011: 532.

Material examined. $2 \widehat{\diamond}$, labeled 'China: Zhejiang Prov. / Jingqing County / BaiYun forest area / 7.v.2012, 1,200 m / Jian-Qing Zhu leg.'.

Distribution. South China: Guangdong; East China: Zhejiang (new provinc record). Remarks. The two male specimens from Zhejiang are readily identified as B. tibialis because they have the male sexual characters (present on antennae and protibiae) and the aedeagal form perfectly agrees with those of the type series from Guangdong.

\section{Acknowledgment}

We thank all the colleagues mentioned in the text for the collection and providing of the valuable specimens. The anonymous reviewer critically read the manuscript and provided helpful comments. The present study is supported by the National Science Foundation of China (No. 31172134) and Shanghai Normal University (Sk201242).

\section{References}

Chandler DS (2001) Biology, morphology, and systematics of the ant-like litter beetles of Australia (Coleoptera: Staphylinidae: Pselaphinae). Memoirs on Entomology International 15: $1-560$.

Yin ZW, Li LZ, Zhao MJ (2011) Batricavus tibialis, a new genus and species of Batrisini from South China (Coleoptera: Staphylinidae: Pselaphinae). Acta Entomologica Musei Nationalis Pragae 51: 529-534. 